\title{
Control of the Arrangement of Dipolar Orientation of Pyrimidine Inside the Conjugated Backbone
}

2001

Vol. 3, No. 2

173-175

\author{
Ken-Tsung Wong* and Chun Che Hsu \\ Department of Chemistry, National Taiwan University, Taipei 106, Taiwan, R.O.C.
}

kenwong@ccms.ntu.edu.tw

Received November 16, 2000

\section{ABSTRACT}

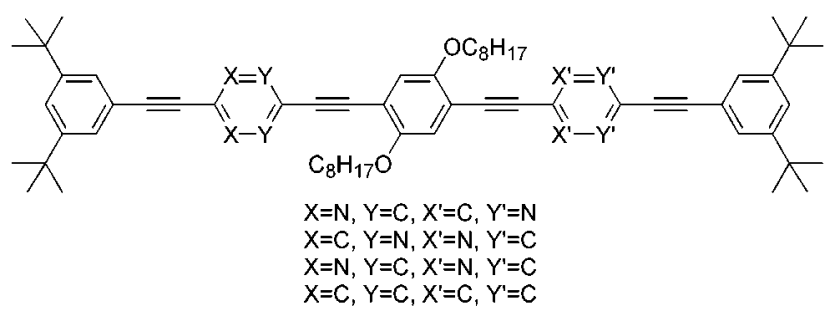

Linear molecules with different arrangement of dipolar pyrimidine moieties in the $\pi$-conjugated backbone were synthesized by a Pd-catalyzed Sonogashira coupling reaction. Significant reduction of the HOMO-LUMO energy band gap and improvement of fluorescence quantum yield were observed upon incorporating pyrimidine into the conjugated backbone.

Linear organic molecules with extended $\pi$-conjugation have received a lot of attention due to their potential use as molecular wires. ${ }^{1}$ Many practical synthetic approaches and testing methods have been developed for constructing and evaluating molecular wires of different lengths. ${ }^{2}$ More interestingly, there has been significant progress in modifying the primary structure of the conjugated system for developing functional molecular wires. ${ }^{3}$ Control of the regioregularity

(1) Lehn, J.-M. Supramolecular Chemistry: Concepts and Perspectives; VCH: Weinheim, 1995. Petty, M. C.; Bryce, M. R.; Bloor, D. Introduction to Molecular Electronics; Edward Arnold: London, 1995.

(2) Tour, J. M. Acc. Chem. Res. 2000, 33, 791.

(3) Marsella, M. J.; Wang, Z.-Q.; Mitchell, R. H. Org. Lett. 2000, 2, 2979. Matsuda, K.; Irie, M. J. Am. Chem. Soc. 2000, 122, 7195. FernandezAcebes, A.; Lehn, J.-M. Chem. Eur. J. 1999, 5, 3285. Jones, N. D.; Wolf, M. O. Organometallics 1997, 16, 1352. Collbert, M. C. B.; Lewis, J.; Long, N. J.; White, A. J. P.; Willams, D. J. J. Chem. Soc., Dalton Trans. 1997, 99. Lebreton, C.; Touchard, D.; Pichon, L. L.; Darido, A.; Toupet, L.; Dixneuf, P. H. Inorg. Chim. Acta 1998, 272, 188. Dembinski, R.; Bartik, T.; Bartik, B.; Jaeger, M.; Gladysz, J. Am. Chem. Soc. 2000, 122, 810. Bruce, M. I.; Low, P. J.; Costuas, K.; Halet, J.-F.; Best, S. P.; Heath, G. A. J. Am. Chem. Soc. 2000, 122, 1949. Kheradmandan, S.; Heinze, K.; Schmalle, H. W.; Berke, H. Angew. Chem., In. Ed. 1999, 111, 2412. Guillemot, M.; Toupet, L.; Lapinte, C. Organometallics 1990, 9, 1992. Bruce, M. I.; Ke, M.; Low, P. J. Chem. Commun. 1996, 2405. Alain, V.; Blachard-Desce, M.; Ledoux-Rak, I.; Zyss, Joseph Chem. Commun. 2000, 353. Slama-Schwok, A.; Blanchard-Desce, M.; Lehn, J.-M. J. Phy. Chem. 1990, 94, 3894. in polymerization is an important issue that results in the formation of polymers with interesting properties by comparison with those of their irregular counterparts. Regioregular poly(pyridine), ${ }^{4}$ ploy(3-alkylthiophene),${ }^{5}$ and oligo(thiophene ethynylenes) ${ }^{6}$ with precise length have been synthesized and have proven to have very interesting optoelectronic, nonlinear properties. We wish to report herein on the synthesis of a new linear $\pi$-conjugated system by manipulating the orientation of the dipolar component in their backbone. This approach will ultimately change the dipolar character of a $\pi$-conjugated system that may lead to the development of an interesting method to probe the structureproperty relationship.

A highly electronegative pyrimidine ring was utilized as the dipolar moiety for incorporation into the conjugated backbone. ${ }^{7}$ The chemoselectivity of 5-bromo-2-iodopyrimidine $\mathbf{1}^{8}$ toward the $\mathrm{Pd}$-catalyzed coupling reaction with

(4) Yamamoto, T.; Maruyama, T.; Zhou, Z. H.; Ito, T.; Fukuda, T.; Yoneda, Y.; Begum, F.; Ikeda, T.; Sasaki, S.; Takezoe, H.; Fukuda, A.; Kubota, K. J. Am. Chem. Soc. 1994, 116, 4832. Gebler, D. D.; Wang, Y. Z.; Blatchford, J. W.; Jessen, S. W.; Lin, L.-B.; Gustafson, Wang, H. L.; Swager, T. M.; MacDiarmid, Esptein, A. J. J. Appl. Phys. 1995, 78, 4264.

(5) McCullough, R. D. Adv. Mater. 1998, 10, 93 and references therein.

(6) Pearson, D. L.; Tour, J. M.J. Org. Chem. 1997, 62, 1367. 
terminal alkynes (Sonogashira coupling reaction) provides us with an effective synthetic strategy for controlling the dipolar orientation of pyrimidine in the conjugated backbone. A very convenient one-pot consecutive Sonogashira coupling procedure has been developed to introduce different alkynyl groups at the 2- and 5-positions of pyrimidine. ${ }^{9}$ In the presence of a catalytic amount of $\mathrm{Pd}\left(\mathrm{PPh}_{3}\right)_{4}, 2$ was synthesized in $74 \%$ yield. 1,4-Diiodo-2,5-dioctylbezene was allowed to react with 2 in the presence of $\mathrm{Pd}\left(\mathrm{PPh}_{3}\right)_{4}$ to provide $3(54 \%)$. This new linear molecule 3 contains five aromatic rings including two pyrimidine rings with two pairs of nitrogen directed away from the central aryl linker (Scheme $1)$.

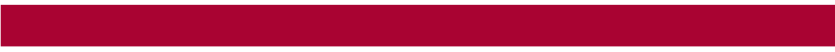

\section{Scheme $1^{a}$}
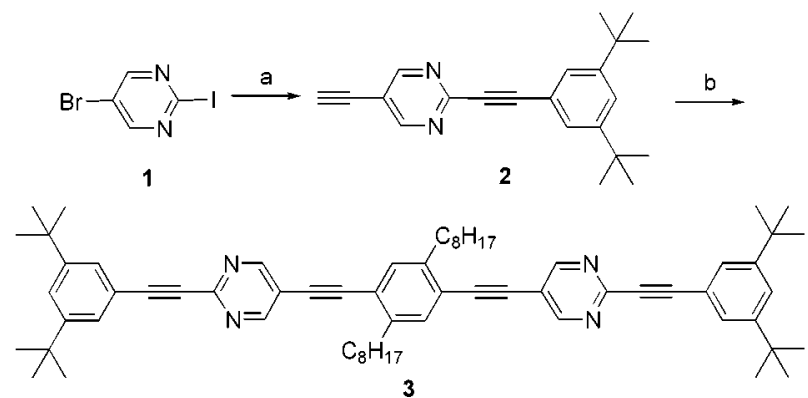

${ }^{a}$ (a) i: 1,3-Di-tert-butyl-5-ethynylbenzene, $\mathrm{Pd}\left(\mathrm{PPh}_{3}\right)_{4}, \mathrm{CuI}$, ${ }^{i} \mathrm{Pr}_{2} \mathrm{NH}$, THF, $30^{\circ} \mathrm{C}$, ii: $\mathrm{Me}_{3} \mathrm{SiC} \equiv \mathrm{CH}$, reflux, iii: $2 \mathrm{~N} \mathrm{NaOH}, \mathrm{THF} /$ $\mathrm{MeOH}, 74 \%$; (b) 1,4-diiodo-2,5-dioctylbenzene, $\mathrm{Pd}\left(\mathrm{PPh}_{3}\right)_{4}, \mathrm{CuI}$, ${ }^{i} \mathrm{Pr}_{2} \mathrm{NH}$, THF, reflux, 54\%.

Treatment of 1 with 1,4-diethynyl-2,5-dioctylbezene in the presence of $\mathrm{Pd}\left(\mathrm{PPh}_{3}\right)_{4}$ afforded dibromo compound 4 in $82 \%$ yield after purification on silica gel. Linear molecule 5,

(7) Gommper, R.; Mari, H.-J.; Polborn, K. Synthesis 1997, 696. Kanbara, T.; Kushida, T.; Saito, N.; Kuwajima, I.; Kubota, K.; Yamamoto, T. Chem. Lett. 1992, 583.

(8) Goodby, J. W.; Hird, M. H.; Lewis, R. A.; Toyne, K. J. Chem. Commun. 1996, 2719.

(9) One-pot consecutive coupling procedure: Under argon, a solution of 5-bromo-2-iodopyrimidine (2.85 g, $10.0 \mathrm{mmol}), \mathrm{Pd}\left(\mathrm{PPh}_{3}\right)_{4}(580 \mathrm{mg}, 0.5$ $\mathrm{mmol})$, CuI (100 mg, $0.5 \mathrm{mmol})$, and ${ }^{\mathrm{i}} \mathrm{Pr}_{2} \mathrm{NH}(2.67 \mathrm{~mL}, 19.0 \mathrm{mmol})$ in THF (40 mL) was stirred for $3 \mathrm{~min}$, and to this was added dropwisely over a period of $3 \mathrm{mim} \mathrm{1,3-di-tert-butyl-5-ethynylbenzene}(2.36 \mathrm{~g}, 11.0 \mathrm{mmol})$ in THF $(10 \mathrm{~mL})$. The mixture was stirred for $2.5 \mathrm{~h}$ at $30^{\circ} \mathrm{C}$. Trimethylsilylacetylene $(1.70 \mathrm{~mL}, 12.0 \mathrm{mmol})$ and ${ }^{{ }^{1}} \operatorname{Pr}_{2} \mathrm{NH}(2.67 \mathrm{~mL}, 19.0 \mathrm{mmol})$ were introduced quickly, and the mixture was heated to reflux for $1.5 \mathrm{~h}$. After cooling to room temperature, the ammonium salt formed was removed by filtration through a short column of aluminum oxide and washed with ether $(2 \times 20 \mathrm{~mL})$. The combined filtrate was concentrated to dryness under reduced pressure. The crude product was dissolved in THF $(20 \mathrm{~mL})$ and methanol $(10 \mathrm{~mL})$, and to this solution was introduced $2.0 \mathrm{~N} \mathrm{NaOH}(5$ $\mathrm{mL}$ ) to remove the silyl group in $20 \mathrm{~min}$ at room temperature. After concentrating in vacuo, water $(20 \mathrm{~mL})$ was added, and the solution was extracted with ether $(2 \times 25 \mathrm{~mL})$. The combined organic solution was dried $\left(\mathrm{MgSO}_{4}\right)$ and concentrated. The residue was purified by column chromatography on silica gel (EtOAc:hexanes $=1: 12$ ) to afford 2 as pale yellow solid (2.34 g, 74\%): mp 202-204 ${ }^{\circ} \mathrm{C}$; IR (KBr) 3274 (s), 2957 (m), 2219 $(\mathrm{s}), 1572(\mathrm{~m}), 1414(\mathrm{~s}), 1180(\mathrm{~m}), 883(\mathrm{~m}), 796(\mathrm{~m}), 706(\mathrm{~m}), 641(\mathrm{~m})$ $\mathrm{cm}^{-1} ;{ }^{1} \mathrm{H} \mathrm{NMR}\left(\mathrm{CDCl}_{3}, 400 \mathrm{MHz}\right) 1.32(\mathrm{~s}, 18 \mathrm{H}), 3.47(\mathrm{~s}, 1 \mathrm{H}), 7.49(\mathrm{t}, J$ $=1.8 \mathrm{~Hz}, 1 \mathrm{H}), 7.55(\mathrm{~d}, J=1.8 \mathrm{~Hz}, 2 \mathrm{H}), 8.81(\mathrm{~s}, 2 \mathrm{H}) ;{ }^{13} \mathrm{C} \mathrm{NMR}\left(\mathrm{CDCl}_{3}\right.$, $100 \mathrm{MHz}) 31.5,35.1,85.8,92.3,116.1,120.2,124.8,127.4,151.3,151.7$ 159.9; MS (m/z, FAB $\left.{ }^{+}\right) 316$ (100), 301 (15), 261 (9), 245 (6), 224 (4), 154 (15), 136 (11), 89 (4), 58 (25); HRMS cacld for $\mathrm{C}_{22} \mathrm{H}_{25} \mathrm{~N}_{2} 317.2018$, found 317.2028. Anal. Cacld for $\mathrm{C}_{22} \mathrm{H}_{24} \mathrm{~N}_{2}$ : C, 83.50; H, 7.64; N, 8.85. Found: C, 83.69; H, 7.38; N, 8.68. similar to $\mathbf{3}$ but with two pairs of pyrimidine nitrogens directed toward the central aromatic linker, can be prepared in $71 \%$ yield by coupling 4 with 1,3-di-tert-butyl-5-ethynylbenzene in the presence of the same catalyst at elevated temperature (Scheme 2).

Scheme $2^{a}$

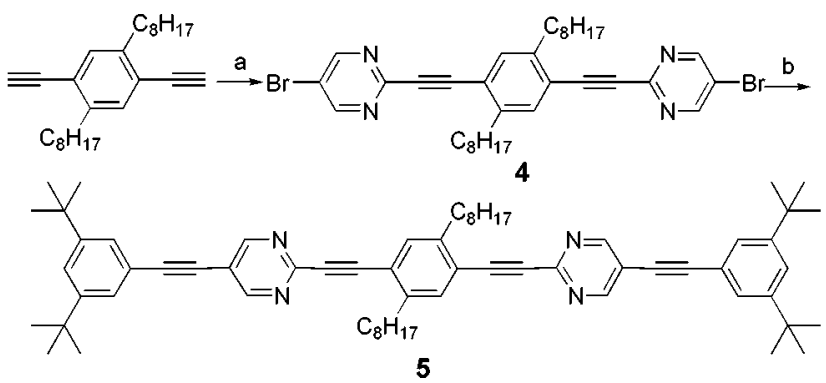

${ }^{a}$ (a) 1, $\mathrm{Pd}\left(\mathrm{PPh}_{3}\right)_{4}, \mathrm{CuI},{ }^{\mathrm{i}} \mathrm{Pr}_{2} \mathrm{NH}, \mathrm{THF}$, room temperature, $82 \%$ (b) 1,3-di-tert-butyl-5-ethynylbenzene, $\mathrm{Pd}\left(\mathrm{PPh}_{3}\right)_{4}, \mathrm{CuI},{ }^{\mathrm{i}} \mathrm{Pr}_{2} \mathrm{NH}$, THF, reflux, $71 \%$.

Synthetic pathways toward linear molecules possessing the same arrangement of the dipolar orientation of pyrimidine in the conjugated backbone are more complicated. First, 1-iodo-4-(trimethylsilylethynyl)-2,5-dioctylbenzene ${ }^{10}$ was treated with 2 at $80{ }^{\circ} \mathrm{C}$ in the presence of $\mathrm{Pd}\left(\mathrm{PPh}_{3}\right)_{4}$ to afford intermediate 6 in $94 \%$ yield. Removal of the TMS group from 6 followed by coupling with $\mathbf{1}$ afforded $\mathbf{7}$ in $90 \%$ yield. Further treatment of 7 with 1,3-di-tert-butyl-5-ethynylbenzene in the presence of $\mathrm{Pd}$ catalyst gave the desired compound $\mathbf{8}$ in $79 \%$ yield (Scheme 3 ).

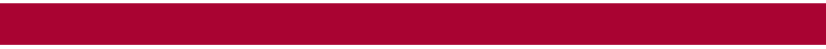

Scheme $3^{a}$
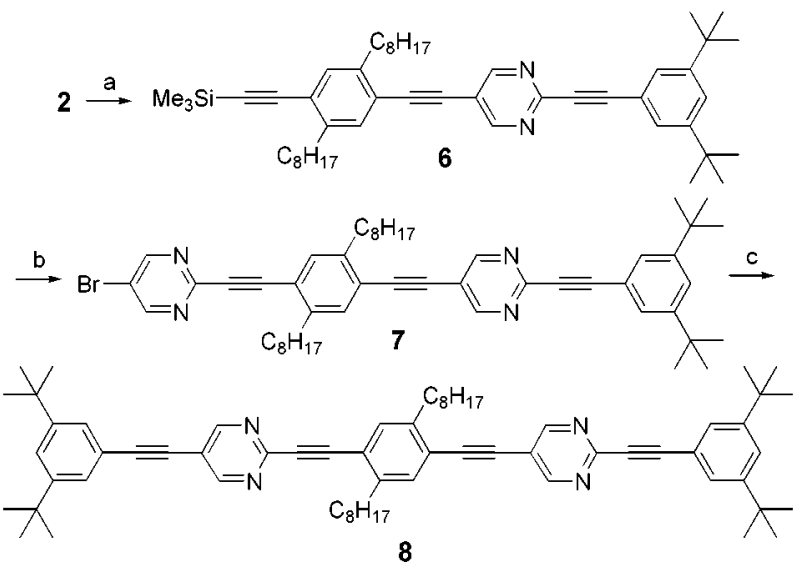

${ }^{a}$ (a) 1-Ethynyl-4-iodo-2,5-dioctylbenzene, $\mathrm{Pd}\left(\mathrm{PPh}_{3}\right)_{4}, \mathrm{CuI},{ }^{\mathrm{i}} \mathrm{Pr}_{2} \mathrm{NH}$, THF, room temperature, $94 \%$; (b) i: $2 \mathrm{~N} \mathrm{NaOH}$, THF/MeOH, ii: 1, $\mathrm{Pd}\left(\mathrm{PPh}_{3}\right)_{4}, \mathrm{CuI},{ }^{\mathrm{P}} \mathrm{Pr}_{2} \mathrm{NH}$, THF, room temperature, $90 \%$; (c) 1,3di-tert-butyl-5-ethynylbenzene, $\mathrm{Pd}\left(\mathrm{PPh}_{3}\right)_{4}, \mathrm{CuI},{ }^{\mathrm{P}} \mathrm{Pr}_{2} \mathrm{NH}, \mathrm{THF}$, reflux, $79 \%$.

Linear molecule 10 (Scheme 4) prepared in a similar manner as that for $\mathbf{5}$ was employed as a reference compound. 


\section{Scheme $4^{a}$}
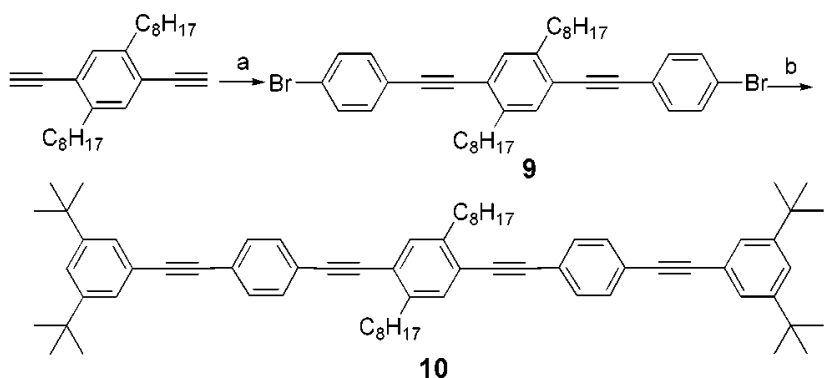

${ }^{a}$ (a) 1-Bromo-4-iodobenzene, $\mathrm{Pd}\left(\mathrm{PPh}_{3}\right)_{4}, \mathrm{CuI},{ }^{\mathrm{i}} \mathrm{Pr}_{2} \mathrm{NH}, \mathrm{THF}$, room temperature, 91\%; (b) 1,3-di-tert-butyl-5-ethynylbenzene, $\mathrm{Pd}\left(\mathrm{PPh}_{3}\right)_{4}, \mathrm{CuI},{ }^{\mathrm{i}} \mathrm{Pr}_{2} \mathrm{NH}, \mathrm{THF}$, reflux, $92 \%$.

Our synthetic protocol provides a successful control of the dipolar orientation of the pyrimidine moiety in the conjugated backbone. The optical properties are demonstrated in their absorption and photoluminescence (PL) spectra (Figure 1).

Linear molecules $\mathbf{3}, \mathbf{5}$, and $\mathbf{8}$ reveal very similar behavior in their photophysical properties. Significant red shifts of $\mathbf{3}$, $\mathbf{5}$, and $\mathbf{8}$ in their absorption maximum $\left(\lambda_{\max } 371 \mathrm{~nm}\right)$ compared with that of the corresponding model compound $10\left(\lambda_{\max } 311 \mathrm{~nm}\right)$ were observed. By inspecting the edge of absorption spectra, the energy band gaps for $\mathbf{3}, \mathbf{5}$, and $\mathbf{8}$ were estimated to be ca. $0.2 \mathrm{eV}$ smaller than that of 10. All the pyrimidine-containing molecules $\mathbf{3}, \mathbf{5}$, and $\mathbf{8}$ exhibit strong blue fluorescence with emission maximum at $406 \mathrm{~nm}$ and a weaker band centered on $428 \mathrm{~nm}$. The photoluminescence also indicates substantial red shifts by $38 \mathrm{~nm}$ relative to that of 10 (364 nm, $384 \mathrm{~nm})$. The PL efficiency of $\mathbf{3}, \mathbf{5}, \mathbf{8}$, and $\mathbf{1 0}$ are $0.63,0.61,0.75$, and 0.34 , respectively. Apparently, the incorporation of pyrimidines inside a defined $\pi$-conjugated system increases the quantum yield of fluorescence.

In conclusion, we have demonstrated methods for controlling the arrangement of dipolar orientation of pyrimidine

(10) Prepared by the literature procedure: Davey, A. P.; Elliott, S.; O’Connor, O.; Blau, W. J. Chem. Soc., Chem. Commun. 1995, 1433.

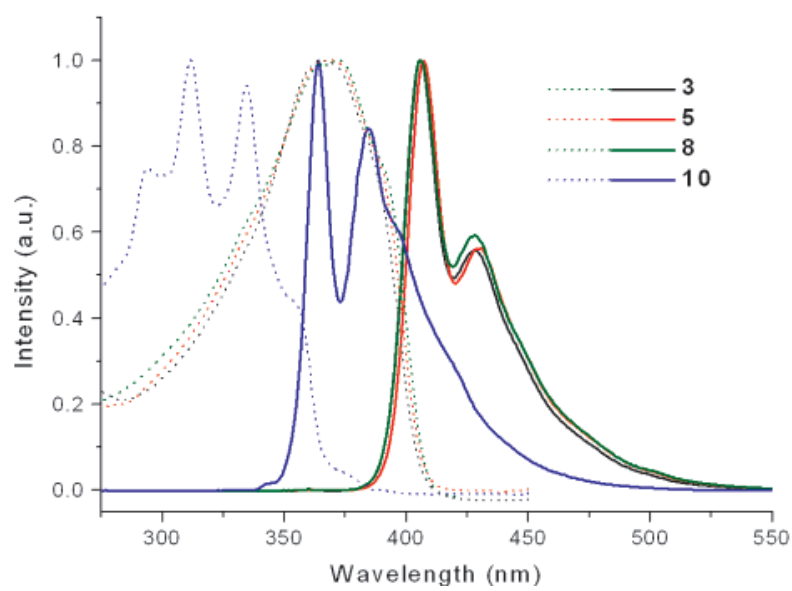

Figure 1. Normalized absorption $\left(\mathrm{CHCl}_{3}, 1 \times 10^{-5} \mathrm{M}\right)$ and photoluminescence $\left(\mathrm{CHCl}_{3}, 5.5 \times 10^{-6} \mathrm{M}\right)$ spectra of pyrimidinecontaining linear compounds $\mathbf{3}, \mathbf{5}$, and $\mathbf{8}$ and model compound $\mathbf{1 0}$.

inside a defined conjugated backbone. Significant reduction of the HOMO-LUMO energy band gap and improvement of fluorescence quantum yield were observed upon incorporating pyrimidine into the conjugated backbone. Further studies on the dependence of electochemical properties on the different arrangement of dipolar orientation are in progress.

Acknowledgment. We gratefully thank the National Science Council (NSC 89-2113-M-002-008) for financial support.

Supporting Information Available: ${ }^{1} \mathrm{H}$ NMR spectra of 3, 4, 5, 6, 7, 8, 9, and 10 and detailed experimental procedures, full characterization. This material is available free of charge via the Internet at http://pubs.acs.org.

OL006877K 